\title{
A Note on Product Differentiation under Concave Transportation Costs*
}

\author{
Carmen Arguedas \\ Universidad Autónoma de Madrid \\ Departamento de Análisis Económico: \\ Teoría Económica e Historia Económica \\ carmen.arguedas@uam.es

\section{Hamid Hamoudi} \\ Universidad Rey Juan Carlos \\ Departamento de Fundamentos del Análisis Económico \\ hamid.hamoudi@urj.es
}

\begin{abstract}
Concavity of transportation costs has been rarely considered in the linear model of product differentiation, although it seems a reasonable assumption in many contexts. In this paper, we extend the results by Gabszewicz and Thisse (1986) about the existence of the sequential first-location-then-price equilibrium to the case where transportation costs are concave in distance. Thus, there exists a unique sequential equilibrium in the model of vertical differentiation which involves maximal differ-

* The authors wish to thank an anonymous referee for his/her comments. Financial support from the Spanish Ministry of Education under research project number 5EJ200505206/ECON is gratefully acknowledged.
\end{abstract}


entiation, while the sequential equilibrium under horizontal differentiation fails to exist. In this latter case, under given locations, firms need not be sufficiently far from each other for a price equilibrium to exist. In fact, a possible equilibrium involves both firms being located near one extreme of the city. In that case, the demand of the furthest firm is non-connected.

Keywords: Hotelling, product differentiation, concave transportation costs, nonconnected demand.

JEL Classification: C72, D43.

\section{INTRODUCTION}

When consumers choose stores, they consider both prices and transportation costs. If two stores charge the same price for a given product, consumers choose to buy at their nearest store, since transportation costs are lower. Stores can attract further consumers only if they charge a sufficiently low price compared to their competitors.

Very frequently, stores attract not only consumers living in their surroundings but also consumers that live far. For example, consider two stores (A and B) and three consumers (1,2 and 3) located along a main street, as in Figure 1.

Figure 1. An example of stores and consumers' locations

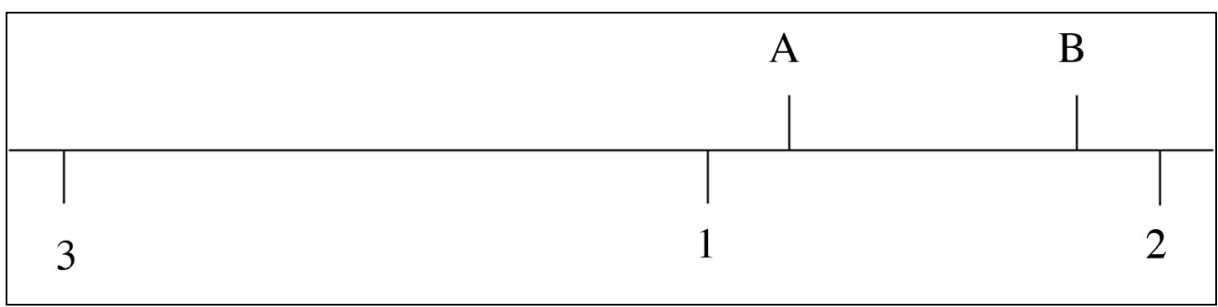

Suppose that consumers 1 and 2 live within walking distance from A and B, respectively, whereas consumer 3 lives far from both stores. Clearly, B can attract consumers 1 and 3 only if the corresponding price (compared to that of $A$ ) is lower than the additional transportation cost of travelling from A to B. Probably, consumer 1 would need a car only if she chooses B while consumer 3 would need it anyway. Consumer l's additional transportation cost of travelling from A to B is then larger 
than that of consumer 3 . Thus, the price reduction in B may be attractive only to consumers 2 and 3 , but not to consumer 1 . In this case, the demand of B is non-connected since consumer 1 (who lives somewhere between consumers 2 and 3 ) does prefer store A.

Surprisingly, the literature on product differentiation has not focussed on this feature, that is, the fact that transportation costs are concave in distance. There, it is assumed that transportation costs are convex and, as a result, demands for firms are connected $^{1}$. Then, B could attract either consumer 2 only, or consumers 1 and 2 , or the three consumers, but not consumers 2 and 3 , since convexity means that consumer 3's additional cost of travelling from A to B is larger than that of consumer 1 .

The purpose of this paper is then to analyze the role of concavity in the linear model of product differentiation, and to compare the results with those under convexity. We consider both the cases of vertical and horizontal differentiation analyzed in Gabszewicz and Thisse (1986) - GT hereafter. Vertical differentiation assumes that both firms locate outside the city, whereas horizontal differentiation refers to the case where both firms locate in the city. In this latter case, we extend the analysis to all possible locations of the firms in the city, whereas GT only consider the case of symmetric locations.

Contrary to GT, where convexity is assumed, we show that it is possible that the furthest consumers choose the furthest firms under both vertical and horizontal differentiation. This is so because competition in prices increases when transportation costs are concave, and the difference in the price is the only relevant variable for consumers located far enough.

In the model of vertical differentiation, we find a unique sequential equilibrium involving maximal separation between the firms, extending the result found in GT to the concave case. However, as a consequence of concavity, the furthest firm only attracts the furthest consumers if both firms serve positive demands. Consider again Figure 1 and ignore consumer 2 (for example, assume there are no consumers living to the right of A). Under concave costs, consumer 3 drives to B whereas consumer 1

1 The literature on product differentiation started with Hotelling (1929) and it is vast, nowadays. For example, D’Aspremont et al. (1979), Economides (1986), Gabszewicz and Thisse (1986) or Anderson (1988), among others, have analyzed the existence of the sequential first-locate-then-price equilibrium in the linear model of product differentiation under alternative convex specifications of the transportation cost function. 
walks to A. By contrast, GT predict that consumer 3 drives to A and consumer 1 drives to $\mathrm{B}$, which is not likely in our example.

Under horizontal differentiation, we confirm that there does not exist a price equilibrium for every possible locations of the firms, as in the convex case. Under convexity, a price equilibrium under given locations may exist only if firms are sufficiently separated. In contrast, under concavity we find two possible equilibria, one involving sufficiently high differentiation and another where both firms are closely located at one extreme of the city. The first type of equilibrium implies that each firm serves a connected demand. The second type, however, implies that the firm closer to the extreme serves a non-connected demand. For example, in the context of Figure 1, stores A and B might be close enough such that consumers 2 and 3 choose B while consumer 1 chooses A.

Clearly, this latter result is novel ${ }^{2}$, and contrasts with the literature that assumes convex transportation costs. Under given locations and concave transportation costs, a price equilibrium may exist if firms are located sufficiently close from each other and sufficiently far from some subset of consumers. If the firm located nearer the extreme sets a lower price, it can attract consumers located at the other extreme, since the price savings outweighs their additional (almost negligible) transportation costs.

Concavity of transportation costs has been considered in the circle model. De Frutos et al. (1999) show that there exists a unique sequential equilibrium when $\mathrm{C}(d)=$ $d-d^{2}$. Moreover, they find that it is possible to find a convex cost function associated to each possible concave function that yields an equivalent game. Therefore, all the results regarding convex transportation costs in the circle model can be applied to the concave case. Unfortunately, this equivalence result does not hold in the linear model, see De Frutos et al. (2002).

The remainder of the paper is organized as follows. In Section 2, we present the model. In Section 3, we study the case of vertical differentiation. In Section 4, we analyze horizontal differentiation. We conclude in Section 5. All the proofs are in the Appendix.

2 To the best of our knowledge, the only paper which shows the possibility of nonconnected demands is Hamoudi and Moral (2005), who analyze the case of horizontal differentiation for the particular transportation cost function $\mathrm{C}(d)=d-d 2$, where $d$ is the distance between the consumer and the firm. 


\section{The Model}

We consider the well-known Hotelling (1929) 's model of spatial differentiation. There, two firms sell a homogeneous product with zero production costs in a linear city of lenght $l$. We consider two alternative cases for the location of the firms. Under vertical differentiation, both firms locate in positions $x_{1}$ and $x_{2}$ outside the city. Without loss of generality, we assume that $l \leq \mathrm{x}_{1} \leq x_{2}$. Under horizontal differentiation, both firms locate in the city, where $0 \leq x_{1} \leq x_{2} \leq l$. For given locations, firms choose mill prices $p_{1}$ and $p_{2}$ that maximize profits, which are obtained multiplying the price times the number of units sold.

Consumers are uniformly distributed along the market. Let $x \in[0, l]$ denote the consumer's location. The distance between the consumer and firm $i$ is defined by $d_{i}=\left|x-x_{i}\right| i=1,2$. We assume that transportation costs are represented by the function $C\left(d_{i}\right)=a d_{i}-b d_{i}^{2}$, where $a \geq 0, b \geq O$ and $l \leq \mathrm{a} / 2 \mathrm{~b}^{3}$. Each consumer buys only one unit of the good at the firm with the lowest total cost, that is, the mill price plus the transportation cost. Therefore, the location of the indifferent consumer satisfies $p_{1}$ $+\mathrm{C}\left(d_{1}\right)=p_{2}+C\left(d_{2}\right)$.

We consider the first-location-then-price equilibrium concept. In the first stage, firms simultaneously decide their locations. In the second stage, firms simultaneously decide prices. We solve the problem backwards to obtain the sub-game perfect equilibrium.

3 We choose a linear-quadratic cost function to directly compare our results with those of GT, whoassume $\mathrm{C}\left(d_{i}\right)=a d_{i}+b d_{i}^{2}$. The analysis of a general concave specification is much more complicated, but it does not yield additional insights. In fact, the feature that the demand can be non-connected is due to the fact that marginal transportation costs are decreasing in distance (a characteristic shared by all concave specifications), and not to the particular functional form chosen. Moreover, any concave specification can be fairly approximated by a second order degree polynomial, as long as third order derivatives are sufficiently small. 


\section{Vertical Differentiation}

We assume that $l \leq x_{1} \leq x_{2} \leq \mathrm{a} / 2 \mathrm{~b}$. Consumers' behavior depends on whether transportation costs are convex or concave. Under convex costs (the case of GT), consumers close to firm 1 are willing to substitute a lower price for a larger transportation cost, buying the product to firm 2 . However, in the concave case, the furthest firm can attract the furthest consumers taking advantage of the decreasing marginal transportation costs.

In the concave case, the indifferent consumer (located at $\tilde{x}$ ) satisfies the following:

$$
p_{1}+a\left(x_{1}-\tilde{x}\right)-b\left(x_{1}-\tilde{x}\right)^{2}=p_{2}+a\left(x_{2}-\tilde{x}\right)-\mathrm{b}\left(x_{2}-\tilde{x}\right)^{2} .
$$

Then, consumers located at $\mathrm{x}>(<) \tilde{x}$ buy the product to firm $1(2)^{4}$. Therefore, the demand of firm 1 is the following (the demand of firm 2 can be easily deducted, since $D_{1}+D_{2}=l$ ):

$$
D_{1}= \begin{cases}l, & 0 \leq p_{1} \leq p_{2}+h \\ l \cdot \frac{H-p_{1}+p_{2}}{H-h}, & p_{2}+h \leq p_{1} \leq p_{2}+H \\ 0, & p_{1} \geq p_{2}+H\end{cases}
$$

where $h=\left(x_{2}-x_{1}\right)\left[a-b\left(x_{2}+x_{1}\right)\right]$ and $H=\left(x_{2}-x_{1}\right)\left[a+b\left(2 l-x_{2}-x_{1}\right)\right]$.

The following proposition presents the Nash-price equilibrium.

Proposition 1 Given $\left(x_{1}, x_{2}\right)$, there exists a unique Nash-price equilibrium given by

4 The opposite holds under convex transportation costs, see GT. 


$$
\begin{array}{lll}
p_{1}^{*}=\frac{2 H-h}{3}, & p_{2}{ }^{*}=\frac{H-2 h}{3}, & \text { if } 2 l+x_{1}+x_{2} \geq a / b \\
p_{1}{ }^{*}=h, & p_{2}{ }^{*}=0, & \text { if } 2 l+x_{1}+x_{2}<a / b
\end{array}
$$

Now, firms choose locations considering their behavior in the price competition stage. In the next proposition, we present firms' optimal locations.

Proposition 2 The sub-game perfect equilibrium under vertical differentiation is the following:

(i) If $l \geq \frac{a}{6 b}$, then $\left\{\left(p_{1}^{N}, x_{1}^{N}\right),\left(p_{2}^{N}, x_{2}{ }^{N}\right)\right\}=\left\{\left(\frac{(a-2 b l)(a+6 b l)}{12 b}, l\right),\left(\frac{(a-2 b l)(a+6 b l)}{12 b}, \frac{a}{2 b}\right)\right\}$

(ii) If $l<\frac{a}{6 b}$, then $\left\{\left(p_{1}^{N}, x_{1}^{N}\right),\left(p_{2}^{N}, x_{2}^{N}\right)\right\}=\left\{\left(\left(x_{2}-l\right)\left[a-b\left(l+x_{2}\right)\right], l\right),\left(0, x_{2}\right)\right\}$

When $l \geq a / 6 b$, firms differentiate as much as they can. Since firm l's dominant strategy is to locate at the end of the city $\left(x_{1}=l\right)$, firm 2's best response is to locate as far as possible $\left(x_{2}=a / 2 b\right)$. Intuitively, for given transportation costs, the city is large and consumers located around $\mathrm{O}$ live very far from the two firms. Thus, firm 2 can attract the furthest consumers with a smaller price than that of firm 1 , since these consumers' incremental cost of travelling from firm 1 to firm 2 is small.

However, if the city is small (that is, when $l<a / 6 b$ ), consumers located around $\mathrm{O}$ live close to firm 1. In this case, the incremental transportation cost from firm 1 to firm 2 (in any possible location of firm 2) is not compensated by the price difference.

Also, firm 2's likelihood of attracting consumers increases with the degree of concavity of transportation costs, that is, when the parameter $b$ relative to $a$ is large. The larger the degree of concavity, the smaller the incremental cost of travelling from firm 1 to firm 2, and the larger firm 2's likelihood of serving a positive demand. 


\section{Horizontal Differentiation}

We now turn to the case where both firms locate in the city. There can be an indifferent consumer in regions $\left[0, x_{1}\right],\left[x_{1}, x_{2}\right]$ or $\left[x_{2}, l\right]$ The indifferent consumer in each region is denoted, respectively, by $\left(\alpha_{1}, \alpha_{2}, \alpha_{3}\right)$.

Depending on the prices, there are either two indifferent consumers $\left(\alpha_{2}\right.$ and either $\alpha_{1}$ or $\left.\alpha_{3}\right)$, or only one $\left(\alpha_{2}\right)$ or none. Given $p_{2}$, the demand of firm 1 is now the following:

$$
D_{1}=\left\{\begin{array}{cl}
l, & p_{1} \in\left[0, I_{1}\left(p_{2}\right)\right] \\
\alpha_{2}+\left(1+\alpha_{3}\right), & p_{1} \in\left[I_{1}\left(p_{2}\right), I_{2}\left(p_{2}\right)\right] \\
\alpha_{2}, & p_{1} \in\left[I_{2}\left(p_{2}\right), I_{3}\left(p_{2}\right)\right] \\
\alpha_{2}-\alpha_{1}, & p_{1} \in\left[I_{3}\left(p_{2}\right), I_{4}\left(p_{2}\right)\right] \\
0 & p_{1} \in\left[I_{4}\left(p_{2}\right),+\infty\right]
\end{array}\right.
$$

where $I_{1}\left(p_{2}\right)=p_{2}-z(a-b z), I_{2}\left(p_{2}\right)=p_{2}-z[a-b(2 l-q)], I_{3}\left(p_{2}\right)=p_{2}+z(a-b q)$ and $I_{4}\left(p_{2}\right)=p_{2}+z(a-b z)$, where $z=x_{2}-x_{1} \in[0, l]$ and $q=x_{1}+x_{2} \in[0,2 l]$.

Note that if $p_{1} \in\left[I_{1}\left(p_{2}\right), I_{2}\left(p_{2}\right)\right]$, there are two indifferent consumers. Here, the consumer located at $l$ chooses firm 1 (the furthest firm) since $p_{1}+C\left(l-x_{1}\right) \leq p_{2}+$ $C\left(l-x_{2}\right)$. Since both firms are sufficiently far from the consumer at $l$, the incremental transportation cost for this consumer outweighs the savings in price. The consumer located at $x_{2}$ chooses firm 2, since $p_{2} \leq p_{1}+C(z)$. In this case, the demand of firm 1 is non-connected, that is, consumers of firm 1 live in the interval $\left[0, \alpha_{2}\right] \cup\left[\alpha_{3}, l\right]$.

If $p_{1} \in\left[I_{2}\left(p_{2}\right), I_{3}\left(p_{2}\right)\right]$, we only have an indifferent consumer at $\alpha_{2}$. Here, the two firms serve connected demands. Using the same reasoning as above, if $p_{1} \in\left[I_{3}\left(p_{2}\right), I_{4}\left(p_{2}\right)\right]$, firm 2 can attract the furthest consumers living in the interval $\left[0, \alpha_{1}\right]$. In this case, the demand of firm 2 is non-connected and its consumers belong to the interval [0, $\left.\alpha_{1}\right] \cup\left[\alpha_{2}, l\right]$.

Now, profits are not concave in the respective price, which is the cause of the price equilibrium non-existence, as we show next.

Consider first the case where both firms' demands are connected, that is, $p_{1} \in\left[I_{2}\right.$ $\left.\left(p_{2}\right), I_{3}\left(p_{2}\right)\right]$. The candidates for a price equilibrium are:

$$
p_{1}^{N}=\frac{1}{3}(a-b z)(q+2 l), \quad p_{2}^{N}=\frac{1}{3}(a-b z)(4 l-q)
$$


Proposition 3. In the model of horizontal differentiation, when firms' demands are connected, the pair $\left(p_{1}{ }^{N}, p_{2}{ }^{N}\right)$, given by (3), constitutes a Nash-price equilibrium if and only if

$$
\left(x_{1}, x_{2}\right) \in Y_{0} \cap\left(Y_{1} \cap Y_{2} \cap Y_{3}\right) \cap\left(Y_{1} \mathrm{~N} \cap Y_{2}^{\prime} \cap Y_{3}^{\prime}\right) .
$$

The set $Y_{0} \cap\left(Y_{1} \cap Y_{2} \cap Y_{3}\right) \cap\left(Y_{1}^{\prime} \cap Y_{2}^{\prime} \cap Y_{3}^{\prime}\right)$ is defined in the Appendix. A price equilibrium of this type does not exist for any possible locations of the firms. For example, under symmetric locations $(q=l)$, the set of locations which guarantees the equilibrium existence must satisfy $z \geq 1 / 2$. The closest locations for which this equilibrium exists are, therefore, $x_{1}=l / 4, x_{2}=3 l / 4$. Comparing our results with those of GT, the equilibrium region in our case is smaller ${ }^{5}$. Price competition increases under concave costs, and firms separate more to avoid a price war.

Interestingly, there exists another type of price equilibrium which does not involve maximum differentiation between firms. This equilibrium implies that one firm's demand is non-connected. Using the same methodology as above when $p_{1} \in\left[I_{1}\left(p_{2}\right)\right.$, $\left.I_{2}\left(p_{2}\right)\right]$, the Nash-price equilibrium candidates in this region are:

$$
p_{1}^{N}=\frac{z}{3 a}(\mathrm{a}-b z)(4 b 1-a), \quad p_{2}^{N}=\frac{z}{3 a}(a-b z)(a+2 b l)
$$

Now, $Z_{0}$, $\left(Z_{1} \cap Z_{2} \cap Z_{3}\right)$ and $\left(Z_{4} \cap Z_{5} \cap Z_{6}\right)$ represent, respectively, the sets of locations which guarantee that equilibrium existence. Again, these sets are defined in the Appendix.

5 In GT, there exist no price equilibrium when $z \leq \min \left\{\frac{1}{3}, \frac{\sqrt{a}}{2 \sqrt{b+} \sqrt{a}}\right\}$ assuming symmetric locations, $l=1$, and given parameters $a$ and $b$ such that $C(d)=a d+b d^{2}$. Considering $l \leq$ $a / 2 b$, the minimum distance between the firms which guarantees a price equilibrium in GT is $1 / 3$. 
Proposition 4. In the model of horizontal differentiation, when firm 1's demand is nonconnected, the pair $\left(p_{1}^{N}, p_{2}{ }^{N}\right)$, given by (4) constitutes a Nash-price equilibrium if and only if

$$
\left(x_{1}, x_{2}\right) \in Z_{0} \cap\left(Z_{1} \cap Z_{2} \cap Z_{3}\right) \cap\left(Z_{4} \cap Z_{5} \cap Z_{6}\right) .
$$

Unfortunately, there does not exist a price equilibrium for all possible locations of the firms. For example, under symmetry, $Z_{0}$ is an empty set. Therefore, this equilibrium exists only under asymmetric locations and when $a / 4 b \leq l \leq a / 2 b$.

Figure 2 illustrates the price equilibrium regions in the particular case where $a=1$, $b=1 / 2$ and $l=1$. Region I corresponds to Proposition 3, where both demands are connected. Region II reflects the results of Proposition 4, where the demand of firm 1 is non-connected. Conversely, the demand of firm 2 is non-connected in region III.

Figure 2. Equilibrium regions when $\mathrm{a}=1, b=1 / 2$ and $l=1$

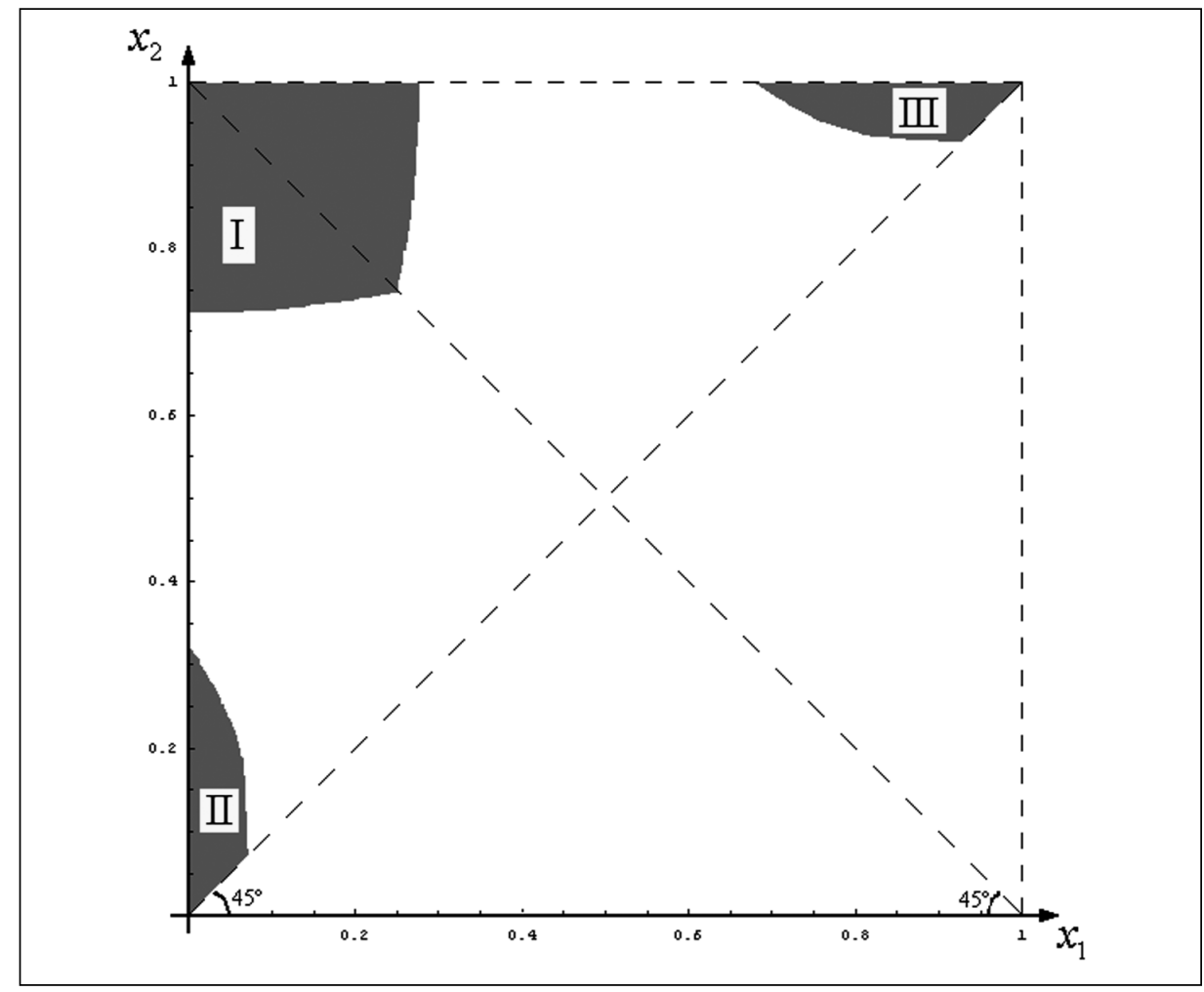


Considering region II, for example, we surprisingly observe that firms need not be far away for a price equilibrium to exist. The reason is that firm 1 serves a nonconnected demand, that is, it attracts the subset of consumers who live in the opposite extreme of the city. Therefore, the distance between firms must be close enough such that the additional transportation cost from firm 2 to firm 1 is compensated by the reduction in the price of firm 1 .

It is possible to graphically show that regions II and III increase with the city length and with the degree of concavity of transportation costs (that is, the parameter b compared to a). Both results are quite intuitive. In fact, the larger the market and the more concave the transportation costs, the lower the additional transportation costs of travelling from the nearest to the furthest firm for the subset of consumers located in the other extreme of the city. Conversely, for sufficiently small market length or small concavity of the transportation costs, regions II and III may fail to exist.

\section{Conclusions}

In this paper, we have studied the case of concave transportation costs in the linear model of product differentiation. In terms of existence of the equilibrium, we have found analogous results to those under convexity. Thus, there exists a unique sequential equilibrium under vertical differentiation, while the price equilibrium under horizontal differentiation only exists under specific conditions on firms' locations. Our analysis then shows the robustness of the existence results to concave transportation costs specifications.

However, this does not mean that there exists an equivalence between the concave and convex cases, as shown in De Frutos et al. (2002). In fact, we have found crucial differences in terms of the characteristics of the demands of the firms and the equilibrium regions, specially in the model of horizontal differentiation.

A distinctive feature under concave costs is that firms' demands can be non-connected. The reason is the decrease in the incremental transportation costs of travelling from one firm to the other when the distance from the consumer to the nearest firm increases. Then, a firm can attract close consumers and also very far consumers, but not consumers that live at an intermediate distance. Therefore, a price equilibrium of this kind exists if both firms asymmetrically locate near one extreme of the city. It is important to emphasize that this equilibrium is possible not due to the allowance of asymmetric locations but to the concavity of the transportation costs. In fact, this 
equilibrium is more likely if the city is large enough and the transportation costs are concave enough. Under these assumptions, we have shown that firms need not be separated for a price equilibrium to exist, a result which clearly contrasts with previous literature on spatial differentiation.

\section{ApPENDIX}

Proof of Proposition 1. It is easy to show that $p_{1}^{*}=\frac{2 H-h}{3}$ and $p_{2}{ }^{*}=\frac{H-2 h}{3}$ are the arguments that maximize profits for each firm, when $h \leq p_{1}-p_{2} \leq H$. This latter condition holds for $\left(p_{1}{ }^{*}, p_{2}{ }^{*}\right)$ when $2 l+x_{1}+x_{2} \geq a / b$. Since profits are quasi-concave, then $\pi_{1}\left(p_{1}^{*}, p_{2}{ }^{*}\right) \geq \pi_{1}\left(p_{1}, p_{2}{ }^{*}\right)$ for all $p_{1} \geq 0$, and $\pi_{2}\left(p_{1}^{*}, p_{2}{ }^{*}\right) \geq \pi_{2}\left(p_{1}{ }^{*}, p_{2}\right)$ for all $p_{2} \geq 0$.

Now, assume $2 l+x_{1}+x_{2}<a / b$. Firm 2 cannot choose a positive price. It could always reduce the price and obtain a positive demand. Firm 1 attracts all the demand if the price is lower or equal to $h$. Therefore, the best price in this interval is $p_{1}^{*}=h$.

For larger prices, profits are $\pi_{1}\left(p_{1}, p_{2}=0, x_{1}, x_{2}\right)=l \cdot \stackrel{H-p_{1}}{\longrightarrow} \cdot p_{1}$. which are decrea$\mathrm{S}$

in $p_{1}$, since $H-2 p_{1}<0$ when $2 l+x_{1}+x_{2}<a / b$.

Proof of Proposition 2. If $l \geq a / 6 b$, firm 2 can always locate sufficiently far from firm 1 to guarantee positive profits, independently of the decision of firm 1 . $\mathrm{T}$

$\mathrm{h}$

a

is, firm 2 can choose $x_{2}$ such that $2 l+x_{1}+x_{2} \geq a / b$. Moreover, we have $\frac{\partial \pi_{1}}{\partial x_{1}} \leq 0$ and $\frac{\partial \pi_{2}}{\partial x_{1}} \geq 0$. Therefore, firms locate in $x_{1}=l$ and $x_{2}=a / 2 b$.

If $l<a / 6 b$, depending on $x_{1}$ and $x_{2}$, both cases $2 l+x_{2}+x_{1} \geq a / b$ and $2 l+x_{2}+x_{1}$ $<a / b$ are possible. Note that $\pi_{1}$ is continuous for all $x_{1}$ since:

$$
\lim _{x_{1} \rightarrow\left(a / b-2 l-x^{2}\right)}\left\{l \frac{(2 H-h)^{2}}{9(H-h)}\right\}=\lim _{x_{1} \rightarrow\left(a / b-2 l-x_{2}\right)}\{l h\}=4 b l^{2}\left(l+x_{2}-\frac{a}{2 b}\right) .
$$


Also, note that $\pi_{1}$ is decreasing in $p_{1}$, because it is decreasing when $2 l+x_{1}+x_{2} \geq a / b$ and also $\frac{\partial \pi_{1}}{\partial x_{1}} \leq 0$ when $2 l+x_{2}+x_{1}<a / b$. Therefore, given $x_{2}$, the best strategy for firm 1 is $x_{1}^{*}=l$. Given $x_{1}^{*}=l$, any location for firm 2 results in $\pi_{2}=0$.

Proof of Proposition 3. Let us define $P_{0}\left(x_{1}, x_{2}\right)=-(z(b(4 l-q)-3 a)-2 a(q-$ $l)), P_{1}\left(x_{1}, x_{2}\right)=-6 l(4 l-q)+(q+2 l)^{2}+18 l z, P_{2}\left(x_{1}, x_{2}\right)=3 z(2 b l+a)-a(4 l-q), P_{3}$ $\left(x_{1}, x_{2}\right)=-\left(3 b z^{2}(a-2 b l)+a z(3 a-2 b l+5 b q)-a^{2}(4 l-q)\right), P_{4}\left(x_{1}, x_{2}\right)=4 a b z(2 l+$ $q)^{2}-(a(4 l-q-3 z)-6 b l z)^{2}, P_{5}\left(x_{1}, x_{2}\right)=-a(4 l-q+3 z)+b z(4 l+5 q-3 z), P_{6}\left(x_{1}\right.$, $\left.x_{2}\right)=4 b z(2 l+q)^{2}-a(4 l-q+3 z)^{2}, P_{j}^{\prime}\left(x_{1}, x_{2}\right)$ in the same way as $P_{j}\left(x_{1}, x_{2}\right)$ and substituting « $q$ » by « $2 l-q$ », and the locations set $A=\left\{\left(x_{1}, x_{2}\right) \in \mathfrak{R}^{2} / 0 \leq x_{1} \leq x_{2} \leq l\right\}$.

Now, (3) constitutes a Nash equilibrium if it belongs to the appropriate range and each firm's price is a best response given the other firm's price. That is, if:

(i) $\quad\left(p_{1}{ }^{N}, p_{2}{ }^{N}\right)$ is such that $p_{1}^{N} \in\left[I_{2}\left(p_{2}{ }^{N}\right) I_{3}\left(p_{2}{ }^{N}\right)\right]$.

(ii) $\pi_{1}\left(p_{1}{ }^{N}, p_{2}{ }^{N}\right) \geq \pi_{1}\left(p_{1}^{N}, p_{2}{ }^{N}\right)$, for all $p_{1}^{N} \geq 0$.

(iii) $\pi_{2}\left(p_{1}^{N}, p_{2}^{N}\right) \geq \pi_{2}\left(p_{1}^{N}, p_{2}\right)$, for all $p_{2} \geq 0$.

Condition (i). Condition $p_{1}{ }^{N} \geq I_{2}\left(p_{2}{ }^{N}\right)$ is equivalent to $P_{0}\left(x_{1}, x_{2}\right) \geq 0$. On the other hand, $p_{1}^{N} \leq I_{3}\left(p_{2}{ }^{N}\right)$ is equivalent to $P_{0}^{\prime}\left(x_{1}, x_{2}\right) \geq 0$. Therefore, locations must be in:

$$
Y_{0}=\left\{\left(x_{1}, x_{2}\right) \in A / P_{0}\left(x_{1}, x_{2}\right) \geq 0, \quad P_{0}^{\prime}\left(x_{1}, x_{2}\right) \geq 0\right\}
$$

Condition (ii). Given $p_{2}{ }^{N}$, when $p_{1} \in\left[0, I_{1}\left(p_{2}{ }^{N}\right)\right]$, $\arg \max \pi_{1}\left(p_{1}, p_{2}\right)=I_{1}\left(p_{2}{ }^{N}\right)$, and $\pi_{1}\left(p_{1}^{N}, p_{2}{ }^{N}\right) \geq \pi_{1}\left(I_{1}\left(p_{2}^{N}\right), p_{2}{ }^{N}\right)$ if $p_{1}\left(x_{1}, x_{2}\right) \geq 0$. Locations that meet this condition belong to:

$$
Y_{1}=\left\{\left(x_{1}, x_{2}\right) \in A / P_{1}\left(x_{1}, x_{2}\right) \geq 0\right\}
$$

When $p_{1} \in\left[I_{1}\left(p_{2}{ }^{N}\right), I_{2}\left(p_{2}{ }^{N}\right)\right]$, define $p_{1}{ }^{*}=\arg \max \pi_{1}\left(p_{1}, p_{2}{ }^{N}\right)$. Then $\pi_{1}\left(p_{1}{ }^{N}, p_{2}{ }^{N}\right)$ $\geq \pi_{1}\left(p_{1}{ }^{*}, p_{2}{ }^{N}\right)$, which hold if and only if $P_{4}\left(x_{1}, x_{2}\right) \geq 0$. On the other hand, $p_{1}{ }^{*} \in\left[I_{1}\right.$ $\left.\left(p_{2}^{N}\right), I_{2}\left(p_{2}^{N}\right)\right]$ if $P_{2}\left(x_{1}, x_{2}\right) \geq 0$ and $P_{3}\left(x_{1}, x_{2}\right) \geq 0$. Then, locations that satisfy these conditions are in: 


$$
Y_{2}=A \backslash\left\{\left(x_{1}, x_{2}\right) \in A / P_{2}\left(x_{1}, x_{2}\right) \geq 0, \quad P_{3}\left(x_{1}, x_{2}\right) \geq 0, \quad P_{4}\left(x_{1}, x_{2}\right)<0\right\} .
$$

When $p_{1} \in\left[I_{3}\left(p_{2}{ }^{N}\right), I_{4}\left(p_{2}^{N}\right)\right]$, the optimal deviation is $p_{1}^{* *}=\arg \max \pi_{1}\left(p_{1}, p_{2}{ }^{N}\right)$. Then, $\pi_{1}\left(p_{1}{ }^{N}, p_{2}{ }^{N}\right) \geq \pi_{1}\left(p_{1}{ }^{* *}, p_{2}{ }^{N}\right)$ if $P_{6}\left(x_{1}, x_{2}\right) \geq 0$ and $p_{1}{ }^{* *} \in\left[I_{3}\left(p_{2}{ }^{N}\right), I_{4}\left(p_{2}{ }^{N}\right)\right]$ if $P_{5}\left(x_{1}, x_{2}\right) \geq \mathrm{O}$. That is, locations must be in:

$$
Y_{3}=A \backslash\left\{\left(x_{1}, x_{2}\right) \in A / P_{5}\left(x_{1}, x_{2}\right) \geq 0, \quad P_{6}\left(x_{1}, x_{2}\right)<0\right\}
$$

Summarizing, locations which satisfy condition (ii) belong to the set $Y_{1} \cap Y_{2} \cap Y_{3}$.

Condition (iii). Following the same procedure for firm 2, and simply interchanging $q$ by $2 l-q$, the set of location for which firm 2 has no incentives to deviate is $Y_{1}^{\prime} \cap Y_{2}^{\prime} \cap Y_{3}^{\prime}$, where $Y_{i}^{\prime}$ is the same as $Y_{i}$ substituting $P_{j}$ by $P_{j}^{\prime}$.

Proof of Proposition 4. Let us define $P_{0}\left(x_{1}, x_{2}\right)=-\left(a^{2}-2 b^{2} l z-a b(4 l-3 q-\right.$ $2 z)), P_{1,1}\left(x_{1}, x_{2}\right)=2 b^{2} l z^{2}-a b z(14 l-3 q-z)+a^{2}(2 q+5 z), P_{1,2}\left(x_{1}, x_{2}\right)=-\left(a^{2}(3 q-\right.$ $\left.7 z)+2 b^{2} l z^{2}-a b z(2 l-3 q-z)\right), P_{1,3}\left(x_{1}, x_{2}\right)=4 a z(a-4 b l)^{2}-b(2 b l z+a(3 q+z))^{2}$, $P_{1,4}\left(x_{1}, x_{2}\right)=a^{4}-2 a^{3} b(4 l+6 q-5 z)+16 b^{4} l^{2} z^{2}-2 a b^{3} l z(16 l-3 q+7 z)+a^{2} b^{2}\left(16 l^{2}\right.$ $\left.-6 l q+9 q^{2}+22 l z-6 q z-2 z^{2}\right), P_{1,5}\left(x_{1}, x_{2}\right)=-\left(2 a^{2}-b^{2} l z+a b(l-3 q+z)\right), P_{2,1}$ $\left(x_{1}, x_{2}\right)=P_{1,1}\left(x_{1}, x_{2}\right)-6 l(a-b z), P_{2,2}\left(x_{1}, x_{2}\right)=P_{1,2}\left(x_{1}, x_{2}\right)+6 l(a-b z)^{2}, P_{2,3}\left(x_{1}, x_{2}\right)$ $=4 a z(a+2 b l)^{2}+b(4 b l z-a(6 l-3 q-z))^{2}, P_{2,4}\left(x_{1}, x_{2}\right)=P_{1,5}\left(x_{1}, x_{2}\right), P_{2,5}\left(x_{1}, x_{2}\right)=$ $-\left(\mathrm{a}^{2}-8 a b l+7 b^{2} l^{2}\right), P_{2,6}\left(x_{1}, x_{2}\right)=P_{1,4}\left(x_{1}, x_{2}\right)+36 b l(a-b l)(a-b z)^{2}$.

Condition (i). $\quad p_{1}^{N} \in\left[I_{1}\left(p_{2}{ }^{N}\right), I_{2}\left(p_{2}{ }^{N}\right)\right]$ or $p_{2}{ }^{N} \in\left[I_{3}\left(p_{1}^{N}\right), I_{4}\left(p_{1}{ }^{N}\right)\right]$ implies that $-z(a-b z) \leq p_{1}{ }^{N}-p_{2}{ }^{N} \leq-z[(a-2 b l)+b q]$. Substituting (4), we note that the first inequality is always satisfied. The second one is satisfied if $P_{0}\left(x_{1}, x_{2}\right) \geq 0$. Thus, locations must belong to the set $Z_{0}=\left\{\left(x_{1}, x_{2}\right) \mathrm{A} / P_{0}\left(x_{1}, x_{2}\right) \geq 0\right\}$.

Condition (ii). Firm 1 has no incentives to deviate to a price $p_{1} \in\left[0, I_{1}\left(p_{2}^{N}\right)\right]$, since its profits would be negative. If firm 1 deviates to a price $p_{1} \in\left[I_{2}\left(p_{2}^{N}\right), I_{3}\left(p_{2}^{N}\right)\right]$, its optimal deviation would be $p_{1}{ }^{*}=\arg \max \pi_{1}\left(p_{1}, p_{2}{ }^{N}\right)$. Then, $p_{1}{ }^{*} \in\left[I_{2}\left(p_{2}{ }^{N}\right), I_{3}\left(p_{2}{ }^{N}\right)\right]$ if $P_{1,1}\left(x_{1}, x_{2}\right) \geq 0$ and $P_{1,2}\left(x_{1}, x_{2}\right) \geq 0$, and $\pi_{1}\left(p_{1}{ }^{N}, p_{2}{ }^{N}\right) \geq \pi_{1}\left(p_{1}{ }^{*}, p_{2}{ }^{N}\right)$ if $P_{1,3}\left(x_{1}, x_{2}\right)$ $\geq 0$. Thus, firm 1 would not have incentives to deviate to this price if locations belong to the set:

$$
Z_{1}=A \backslash\left\{\left(x_{1}, x_{2}\right) \in A / P_{1,1}\left(x_{1}, x_{2}\right) \geq 0, P_{1,2}\left(x_{1}, x_{2}\right) \geq 0, P_{1,3}\left(x_{1}, x_{2}\right)<0\right\} .
$$


If $\mathrm{p}_{1}^{*}>I_{3}\left(p_{2}{ }^{N}\right), \pi_{1}\left(p_{1}, p_{2}{ }^{N}\right)$ is increasing in $p_{1}$ when $p_{1} \in\left[I_{2}\left(p_{2}{ }^{N}\right), I_{3}\left(p_{2}{ }^{N}\right)\right]$. Thus, we have to guarantee $\pi_{1}\left(p_{1}^{N}, p_{2}{ }^{N}\right) \geq \pi_{1}\left(I_{3}\left(p_{2}{ }^{N}\right), p_{2}{ }^{N}\right)$, which is true for locations in the set:

$$
Z_{2}=A \backslash\left\{\left(P_{2,2}\left(x_{1}, x_{2}\right) \geq 0\right) \in A / P_{1,2}\left(x_{1}, x_{2}\right)<0, P_{1,4}\left(x_{1}, x_{2}\right)<0\right\} .
$$

Now, assume that firm 1 deviates to $p_{1} \in\left[I_{3}\left(p_{2}{ }^{N}\right), I_{4}\left(p_{2}{ }^{N}\right)\right]$. Its optimal price would be $p_{1}^{* *}=\arg \max \pi_{1}\left(p_{1}, p_{2}{ }^{N}\right)$. Then, $p_{1}^{* *} \geq I_{3}\left(p_{3}{ }^{N}\right)$ holds if $P_{1,5}\left(x_{1}, x_{2}\right) \geq 0$ and $p_{1}^{* *} \leq I_{4}\left(p_{4}{ }^{N}\right)$ holds always for all values. Firm's profits are $\pi_{1}\left(p_{1}^{* *}, p_{2}{ }^{N}\right)$, but in this case $\pi_{1}\left(p_{1}^{N}, p_{2}^{N}\right)<\pi_{1}\left(p_{1}^{* *}, p_{2}^{N}\right)$, so locations must be in

$$
Z_{3}=A \backslash\left\{\left(x_{1}, x_{2}\right) \in A / P_{1,5}\left(x_{1}, x_{2}\right) \geq 0\right\}
$$

Firm 1 has no incentives to deviate to $p_{1}>I_{4}\left(p_{2}{ }^{N}\right)$, since demand and profits would be zero.

Thus, $\pi_{1}\left(p_{1}^{N}, p_{2}^{N}\right) \geq \pi_{1}\left(p_{1}, p_{2}^{N}\right)$ for all $p_{1}$ if $\left(x_{1}, x_{2}\right) \in Z_{1} \cap Z_{2} \cap Z_{3}$.

Condition (iii). Following the same procedure for firm 2, we obtain the remaining conditions for the locations of the firms. It has no incentives to deviate to a price $p_{2} \in\left[0, I_{1}\left(p_{1}^{N}\right)\right]$, since its profits would be negative. Now, assume that firm 2 deviates to $p_{2} \in\left[I_{1}\left(p_{1}{ }^{N}\right), I_{2}\left(p_{1}{ }^{N}\right)\right]$. Its optimal price would be $p_{2}{ }^{*}=\arg \max \pi_{2}\left(p_{1}{ }^{N}\right.$, $\left.p_{2}\right)$. Then, $p_{2}{ }^{*} \geq I_{1}\left(p_{1}{ }^{N}\right)$ holds always and $p_{2}{ }^{*} \leq I_{2}\left(p_{1}{ }^{N}\right)$ holds if $P_{2,4}\left(x_{1}, x_{2}\right) \geq 0$. Firm's profits are $\pi_{2}\left(p_{1}{ }^{N}, p_{2}{ }^{*}\right)$, and $\pi_{2}\left(p_{1}{ }^{N}, p_{2}{ }^{N}\right) \geq \pi_{2}\left(p_{1}{ }^{N}, p_{2}{ }^{*}\right)$ if $P_{2,5}\left(x_{1}, x_{2}\right) \geq 0$, so locations must be in the set:

$$
Z_{4}=A \backslash\left\{\left(x_{1}, x_{2}\right) \in A / P_{2,4}\left(x_{1}, x_{2}\right) \geq 0, P_{2,5}\left(x_{1}, x_{2}\right)<0\right\}
$$

If $p_{2}{ }^{*}>I_{2}\left(p_{1}^{N}\right), \pi_{2}\left(p_{1}^{N}, p_{2}^{*}\right)$ is increasing in $p_{2}$ when $p_{2} \in\left[I_{1}\left(p_{1}^{N}\right), I_{2}\left(p_{1}^{N}\right)\right]$. Thus, we have to guarantee $\pi_{2}\left(p_{1}^{N}, p_{2}^{N}\right) \geq \pi_{2}\left(p_{1}^{N}, I_{2}\left(p_{1}^{N}\right)\right)$, which is true for locations in the set

$$
Z_{5}=A \backslash\left\{\left(x_{1}, x_{2}\right) \in A / P_{2,6}\left(x_{1}, x_{2}\right)<0\right\}
$$

If firm 2 deviates to a price $p_{2} \in\left[I_{2}\left(p_{1}^{N}\right), I_{3}\left(p_{1}^{N}\right)\right]$, its optimal price would be $p_{2}{ }^{* *}=\arg \max \pi_{2}\left(p_{1}{ }^{N}, p_{2}\right)$.

Then, $p_{2}^{* *} \in\left[I_{2}\left(p_{1}^{N}\right), I_{3}\left(p_{1}^{N}\right)\right]$ if $P_{2,1}\left(x_{1}, x_{2}\right) \geq 0$ and $P_{2,2}\left(x_{1}, x_{2}\right) \geq 0$. If both con- 
ditions hold, $\pi_{2}\left(p_{1}{ }^{N}, p_{2}{ }^{N}\right) \geq \pi_{2}\left(p_{1}{ }^{N}, p_{2}^{* *}\right)$ if $P_{2,3}\left(x_{1}, x_{2}\right) \geq 0$. Firm 1 would not have incentives to deviate to this price if locations are in

$$
Z_{6}=A-\left\{\left(x_{1}, x_{2}\right) \in A / P_{2,1}\left(x_{1}, x_{2}\right) \geq 0, P_{2,2}\left(x_{1}, x_{2}\right) \geq 0, P_{2,3}\left(x_{1}, x_{2}\right)<0\right\} .
$$

Firm 2 has no incentives to deviate to $P_{2}>I_{4}\left(p_{1}^{N}\right)$, since its demand and profits would be zero. Thus, $\pi_{2}\left(p_{1}{ }^{N}, p_{2}{ }^{N}\right) \geq \pi_{2}\left(p_{1}{ }^{N}, p_{2}\right)$ for all $p_{2}$ if $\left(x_{1}, x_{2}\right) \in Z_{4} \cap Z_{5} \cap Z_{6}$. Finally, combining the three conditions, we obtain the desired result.

\section{REFERENCES}

[1] Anderson, Simon P. (1988), «Equilibrium Existence in the Linear Model of Spatial Competition», Economica, 55, 479-491.

[2] D’Aspremont, Claude; Gabszewicz, J. Jaskold and Thisse, Jacques-Francois (1979), «On Hotelling's Stability in Competition», Econometrica, 47 (5), 1145-1150.

[3] De Frutos, María Ángeles; Hamoudi, Hamid and Jarque, Xavier (1999), «Equilibrium Existence in the Circle Model with Linear Quadratic Transport Costs», Regional Science and Urban Economics, 29 (5), 605-615.

[4] DeFrutos, María Ángeles; Hamoudi, Hamid and J JRQue, Xavier (2002), «Spatial Competition with Concave Transport Costs», Regional Science and Urban Economics, 32, 531-540.

[5] Economides, Nicholas (1986), «Minimal and Maximal Product Differentiation in Hotelling's Duopoly», Economic Letters, 21(1), 67-71.

[6] Gabszewicz, J. Jaskold and Thisse, Jacques-Francois (1986), «On the Nature of Competition with Differentiated Products», The Economic Journal, 96, 160-172.

[7] Hamoudi, Hamid and Moral, María José (2005), «Equilibrium Existence in the Linear Model: Concave versus Convex Transport Costs», Papers in Regional Science, 84, 201-219.

[8] Hotelung, Harold (1929), «Stability in Competition», The Economic Journal, 39 (153), 41-57. 